\title{
Silver Nanoparticles Decorated on Graphene Oxide Sheets for Electrochemical Detection of Ascorbic Acid(AA) in Human Urine Sample
}

\author{
Karthika pichaimuthu ${ }^{2}$, Murugan Keerthi ${ }^{1}$, Shen-Ming Chen ${ }^{1, *}$, Tse-Wei Chen ${ }^{1}$, Chaochin Su ${ }^{2}$ \\ ${ }^{1}$ Department of Chemical Engineering and Biotechnology, National Taipei University of Technology, \\ No.1, Section 3, Chung-Hsiao East Road, Taipei 106, Taiwan. \\ ${ }^{2}$ Institute of Organic and Polymeric Materials, National Taipei University of Technology, Taipei \\ 10608, Taiwan

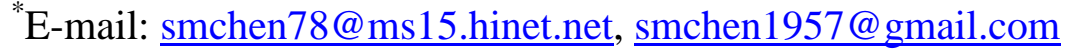

doi: $10.20964 / 2018.08 .16$

Received: 13 April 2018 / Accepted: 3 June 2018 / Published: 5 July 2018

\begin{abstract}
Here, we report a non-enzymatic Silver nanoparticle-decorated graphene oxide (Ag NPs-GO) nanocomposite based electrochemical biosensor for the detection of ascorbic acid using the ultrasensitive electrochemical method. In this work, Ag NPs-GO nanocomposite synthesized through simple and cost-effective ultra-sonication method. As produced composite was characterized by FESEM, TEM, EDX, FT-IR, XRD, EIS and electrochemical methods. The electrochemical behavior of ascorbic acid at the surface of Ag NPs-GO nanocomposite modified screen-printed carbon electrode (SPCE) was investigated by cyclic voltammetry (CV) technique while ascorbic acid sensing was performed by Differential pulse voltammetry method. The as-developed biosensor exhibited lower detection limit of $25 \mathrm{nM}$ and the sensitivity is $1.71 \mu \mathrm{A} \mu \mathrm{M}^{-1} \mathrm{~cm}^{-2}\left(R^{2}=0.997\right)$ towards ascorbic acid in the linear range of $1-210 \mu \mathrm{M}$ with no surface fouling was observed. To evaluate the practical application, the detection of AA performed in the real sample of human urine and vitamin $\mathrm{C}$ tablets to predict unknown concentrations of in the PBS $\mathrm{pH} 7.0$.
\end{abstract}

Keywords: non-enzymatic biosensor; Ultra-sonication method; Ag NPs-GO nanocomposite; ascorbic acid; Electrochemical detection

\section{$\underline{\text { FULL TEXT }}$}

(C) 2018 The Authors. Published by ESG (www.electrochemsci.org). This article is an open access article distributed under the terms and conditions of the Creative Commons Attribution license (http://creativecommons.org/licenses/by/4.0/). 